\title{
When to use belimumab in SLE: case report
}

Ana Carolina Schönrock Carolina Schönrock (UNIPLAC, Lages, SC, Brasil), Maria Giovanna Manenti Giovanna Manenti (UNIPLAC, Lages, SC, Brasil), Danielle Antunes Daronch Antunes Daronch (UNIPLAC, Lages, SC, Brasil)

\section{BACKGROUND}

We report a case of cutaneous and articular lupus refractory to Methotrexate $25 \mathrm{mg} /$ week associated with Azathioprine $3 \mathrm{gr} / \mathrm{kg} / \mathrm{day}$, Hydroxychloroquine $400 \mathrm{mg} /$ day, Tacrolimus $50 \mathrm{mg} / \mathrm{day}$ and Prednisone 0.5$1 \mathrm{mg} / \mathrm{kg} /$ day. Dapsone was not prescribed due to previous history of seizure on medication. After initiating Belimumab, cutaneous lesions of chronic and subacute lupus disappeared, as did the polyarthritis picture.

\section{CASE REPORT}

J.S., 32 years, diagnosed with SLE for 5 years. At the onset of the disease, Cyclophosphamide was administered to class IV lupus nephritis and maintenance with azathioprine. After 3 years of lupus inactivity, with the use of Hydroxychloroquine $400 \mathrm{mg} /$ day, they started lesions of subacute and chronic lupus and small articular migratory polyarthritis with anti-DNA + and low C3 and C4. Instituted Methotrexate $25 \mathrm{mg} /$ week and Prednisone $0.5 \mathrm{mg} / \mathrm{kg}$ with clinical persistence. Associated with azathioprine and increased its dose progressively up to $3 \mathrm{mg} / \mathrm{kg} / \mathrm{day}$, as well as prednisone to $1 \mathrm{mg} / \mathrm{kg}$ / day, with partial improvement of the condition. In an attempt to decrease the dose of Pednisone, the skin lesions and the polyarthritis picture returned. Associate Tacrolimus 50mg / day with improvement of discoid lesions, but persistent outbreaks of acute lupus (Fig 1), polyarthritis (Fig 2) and immunological laboratory abnormalities. After performing Belimumab 10mg / kg intravenously, on days 0, 14 and 28 and after every 4 weeks, the cutaneous and articular condition was stable. Currently, the patient has been using Belimumab for 4 months, without Prednisone, with a lower dose of Azathioprine and with a suspension plan for this and Methotrexate as well as Tacrolimus.

\section{CONCLUSION}

The use of Belimumab in SLE is very well indicated in those cases of non-severe lupus (kidney and CNS), that is, in cutaneous and articular lesions refractory to conventional treatment. Their recent discovery has brought significant improvement in the quality of life for those patients dependent on corticosteroids. 